\title{
Os direitos do trabalho em início do século XXI: Depoimento de Arnaldo Sussekind
}

\author{
Angela de Castro Gomes*
}

\section{Introdução}

A QUESTÃO DAS TRANSFORMAÇÕES do processo de trabalho e das relações entre empregados e empregadores, ocorridas nas últimas décadas do século XX, constitui o pano de fundo dessas reflexões. Elas procuram abordar tal questão, que atinge de formas diferenciadas toda a economia internacional, por meio do exame do debate desencadeado pelas propostas de alteração da legislação trabalhista brasileira, que se acelerou nos últimos anos da década de 1990, quando o país passou a ter um governo identificado com os princípios de uma economia neoliberal.

O ponto de partida proposto é o projeto de lei visando a flexibilização da legislação trabalhista, que o governo Fernando Henrique Cardoso acabou de encaminhar e aprovar na Câmara dos Deputados, em 4 de dezembro de 2001. As circunstâncias que envolveram a votação da proposta governamental evidenciaram vários pontos que merecem registro. Em primeiro lugar, como lideranças sindicais e políticas, além de economistas e juristas, dividiram-se face à proposta, revelando o caráter complexo e polêmico do que estava em pauta. Em segundo lugar, como houve mobilização em torno da questão, pois além das

* Universidade Federal Fluminense; CPDOC-Fundação Getúlio Vargas. 
previsíveis manifestações contrárias e favoráveis de trabalhadores, houve uma grande cobertura da imprensa, o que denota o interesse que ela despertou na sociedade em geral. Em terceiro lugar, como as sessões de votação foram agitadas, sendo marcadas por debates acirrados entre parlamentares e por incidentes considerados suspeitos, o que denota como esse era um projeto fundamental para o governo e de difícil posicionamento para muitos políticos ${ }^{1}$.

Todos esses recentes acontecimentos têm como grande tema a regulamentação do mercado de trabalho, particularmente o escopo dos direitos que devem ser assegurados aos trabalhadores nas atuais condições da economia brasileira. Ou seja, que tipo de relações devem agora presidir os contratos de trabalho e, principalmente, qual o papel da legislação - da intervenção/regulação do Estado - nesses contratos. Questões que têm uma história e que foram objeto de aprendizado e vivência por parte de trabalhadores, patrões e Estado.

Por essa razão, todo esse debate necessariamente remete à chamada Consolidação das Leis Trabalhistas, a CLT, isto é, ao corpo legislativo que tem origem nas décadas de 1930 e 1940, e que regulamentou de forma geral os direitos dos trabalhadores no Brasil. A CLT, de 1943, reunindo um conjunto de leis anteriores e "consolidando-as", assinalou um ponto de inflexão nas relações entre Estado e Sociedade no Brasil, inaugurando uma nova fase das relações de trabalho. A CLT, portanto, precisa ser vista não só como um marco para questões que influenciam decisivamente a economia do país, mas igualmente como integrante de um pacto político que consagrou direitos sociais até então pouco praticados e conhecidos pala população trabalhadora ou não. Por isso, tal conjunto de direitos demarcou uma certa experiência histórica de acesso à cidadania, além de consagrar práticas no mundo do trabalho, que construíram uma cultura política que atingiu os sindicatos de trabalhadores e as associações empresarias.

Pode-se dizer com segurança que, no início do século XXI, há um razoável consenso quanto à necessidade de mudanças nesse corpo

Na sessão do dia 27 de novembro de 2001, considerada tranqüila para aprovação do projeto, após os parlamentares votarem eletronicamente, ocorreu uma pane no painel da Câmara, o que causou tumultos, obrigou a suspensão dos trabalhos e a marcação de uma nova sessão para o dia 4 de dezembro. 
legislativo, considerado desatualizado, pois elaborado durante um regime autoritário e quando o país iniciava seu processo de industrialização. O problema, por conseguinte, não reside em um diagnóstico de que a CLT deve ser reformada. Ele é mais complexo e refere-se ao tipo das mudanças que devem ser realizadas, principalmente no que diz respeito ao grau de presença do Estado no mercado de trabalho, assegurando direitos entendidos por muitos como integrantes da própria idéia de cidadania dos brasileiros. Isso significa discutir tanto o que pode ser mudado na CLT, quanto como e por quem tais mudanças devem ser realizadas.

Para enfrentar o tema, esse texto vai se valer do depoimento de um homem que teve uma posição estratégica no processo de regulamentação das leis do trabalho no Brasil e que, em função do recente projeto governamental, ocupou com destaque as páginas de vários jornais de grande circulação, emitindo sua opinião. Trata-se do jurista Arnaldo Sussekind, último sobrevivente da comissão que elaborou a Consolidação das Leis do Trabalho, e que se considera uma espécie de "irmão mais velho da CLT". Nessa ocasião, o Brasil vivia sob um regime autoritário, chamado Estado Novo (1937-45) que, ao mesmo tempo, eliminou os direitos políticos no país e deu grande incremento aos direitos sociais, cujo maior símbolo foi a própria CLT.

Desde então, Sussekind fez carreira no campo do Direito do Trabalho e transitou por altas instâncias governamentais, chegando mesmo a ser ministro do Trabalho e da Previdência Social de 1964 a 1967, quando um novo regime autoritário voltou a se implantar no Brasil. Durante décadas, portanto, ele acompanhou os debates sobre a questão do trabalho, nacional e internacionalmente, participando de maneira estratégica em algumas decisões, e voltando, mais uma vez, em fins do ano de 2001, a expor suas opiniões. O que se fará a seguir é explorar algumas de suas idéias, a partir das declarações que concedeu recentemente à imprensa, mas trabalhando, fundamentalmente, com o depoimento que concedeu entre maio e julho de 2001, logo, antes do encaminhamento do projeto à Câmara ${ }^{2}$.

2 Depoimento recolhido por Angela de Castro Gomes e Elina Peçanha, integrando o projeto de História do Direito do Trabalho no Brasil, desenvolvido pelo LABHOIUFF e AMORJ-UFRJ, com apoio da FAPERJ. O depoimento foi gravado na residência do entrevistado, na cidade do Rio de Janeiro, e perfaz cerca de 16 horas de gravação. 
Trata-se de uma longa entrevista, que oferece muitas possibilidades, da qual apenas dois pontos serão explorados tendo em vista os objetivos específicos desse texto. Primeiro: como Sussekind, um autêntico personagem-símbolo da chamada Era Vargas, defende a necessidade de reforma da CLT, mas acusa o projeto do governo que visa flexibilizá-la de "impróprio e inoportuno", colocando-se contra uma "concepção neoliberal de acabar com tudo o que é direito para que a lei de mercado prevaleça”. Segundo: como Sussekind, um dos mais ativos representantes do Brasil na Organização Internacional do Trabalho (OIT), avalia a importância desse tipo de instituição nos rumos da política trabalhista de países que, como o Brasil, vêem sua legislação sendo ameaçada por concepções que não levam em conta convenções ratificadas e consagradas internacionalmente ${ }^{3}$.

Mas antes de se dedicar à análise dos pontos da entrevista, o texto procura dar algumas informações mais gerais ao leitor. Inicialmente, a preocupação é situar um pouco da história dos direitos do trabalho no Brasil, assinalando a criação do ministério do Trabalho, Indústria e Comércio como marco fundamental, e acompanhando algumas de suas transformações. Em seguida, trabalha-se mais de perto com a trajetória de Arnaldo Sussekind, de forma a que se possa compreender melhor o ambiente político e intelectual em que foi socializado, bem como algumas de suas marcantes experiências no trato do Direito do Trabalho. Finalmente, são apontadas suas avaliações quanto às questões da reforma da CLT, da impropriedade do recente projeto do governo Fernando Henrique Cardoso e do papel que a OIT pode ter em casos como o que o Brasil vive hoje.

\section{Direito do trabalho e cidadania no brasil}

As questões que envolvem a organização do mercado de trabalho em um país, ou seja, as relações legais que presidem os contratos firmados

"Governo vai violar acordo da OIT: entrevista com Arnaldo Sussekind", Jornal do Brasil, Caderno de Economia, 26 de novembro de 2001, p. 12 e "O projeto é impróprio e inoportuno: um dos criadores da CLT critica proposta de flexibilização do governo", O Globo, Caderno de Economia, 2 de dezembro de 2001, p. 45 
entre patrões e empregados e toda a série de direito e deveres que cada parte assume perante a outra e perante o Estado e a Sociedade, costuma ser um tema fundamental e também conflituoso da história que nos habituamos a chamar de acesso à cidadania. No caso, de uma dimensão da cidadania vinculada aos direitos sociais (diferenciados dos civis e políticos, mas a eles vinculados), que dizem respeito, por exemplo, à educação e à saúde, mas que também e em grande parte, ancoram-se nos chamados direitos do trabalho.

Esses direitos, por sua vez, abarcam uma série de domínios, pois podem significar a criação de normas reguladoras para aqueles que estão trabalhando (horários, férias, salários etc) e para aqueles que não mais trabalham (auxílios, aposentadorias, pensões etc), além de incluir questões da organização do próprio mundo do trabalho e de suas manifestações (associações de empregados e de patrões, direito de greve etc). Um conjunto numeroso e diferenciado de questões práticas e absolutamente cruciais para a organização econômica, social e política de qualquer país, e que precisa ser institucionalizado legalmente.

Internacionalmente, esse processo exigiu o aparecimento de instâncias formais que se especializassem no trato dos direitos do trabalho, com destaque para aquelas de atuação do Estado, ator relevante na implementação desses direitos, bem como em sua fiscalização e permanente transformação. Por tal razão, um momento importante na constituição dos direitos do trabalho na história de um país é o da criação de uma instância governamental de âmbito nacional especialmente encarregada de enfrentar e regulamentar tais direitos: o ministério do Trabalho. Mas como os direitos do trabalho se transformam, geralmente expandindo-se para abarcar um maior número de trabalhadores ou para reconhecer novas demandas sociais (ao menos até o fim do século XX), os ministérios do Trabalho também se transformam, assumindo formatos organizacionais diversos e postulando para si objetivos específicos, conforme a conjuntura histórica nacional e internacional que atravessa sua atuação.

No Brasil não foi diferente (ver Gomes, 1992). O primeiro ministério desse tipo nasceu como um Ministério do Trabalho, Indústria e Comércio. Ele foi um dos principais e mais simbólicos atos da chamada Revolução de 1930, tendo sido criado menos de dois meses após a irrupção da revolta que assinalou o fim da República "Velha", conforme 
terminologia dos próprios "revolucionários". "Velha”, entre outras razões, porque não encarava questões "novas" como a da necessidade de instauração de direitos sociais, entre os quais os do trabalho, fundamentais para o desenvolvimento de um país que precisava se modernizar. Tarefa urgente e que, para os dirigentes políticos daquele momento, cumpria ao Estado liderar. Economia, trabalho e modernização eram a tríade que presidia o novo ministério, não casualmente reunindo, sob a égide do Estado, os “empregados e os empregadores", também segundo a terminologia que se consagra na época. O Ministério do Trabalho, Indústria e Comércio, ao lado do Ministério da Educação e Saúde, ambos ministérios revolucionários, marcavam, no Brasil, o início de um período tanto de forte intervenção estatal, quanto de efetiva implementação de direitos sociais.

Até os anos 1960, atravessando o período da experiência liberaldemocrática iniciada em 1945, quando a força intervencionista do Estado brasileiro recua, mas os direitos sociais avançam ao lado dos políticos, esse é o formato da pasta. A primeira alteração que ela vai sofrer data de fins do governo Juscelino Kubitschek (1955-1960), e vinculase à aprovação da Lei Orgânica da Previdência Social, que tramitou no Congresso Nacional por treze anos, de 1947 a 1960. Com sua aprovação, o "ministério da revolução" desdobra-se em dois: o da Indústria e Comércio e o do Trabalho e Previdência Social. Esse novo formato indicava o crescimento da importância das questões da previdência social no Brasil, processo que não será interrompido pelo movimento militar que eclode em 1964, inaugurando uma nova experiência de autoritarismo no país. É no curso dessa experiência, precisamente quando da chegada à presidência do general Ernesto Geisel, em 1974, que a pasta sofre uma nova alteração. Desta feita, e ainda em função do crescente espaço que as questões previdenciárias vinham ganhando, ela se desdobra mais uma vez: Trabalho sob um comando e Previdência e Assistência Social sob outro.

Toda essa incursão tem como finalidade situar a atuação de Arnaldo Sussekind, que possui dois grandes momentos de destaque. O do início dos anos 1940, durante o Estado Novo, quando ainda muito jovem torna-se um dos homens de confiança do então poderoso ministro do Trabalho, Indústria Comércio, Alexandre Marcondes Filho. E o de meados dos anos 1960, no início do regime militar, quando ele se 
torna ministro do Trabalho e Previdência Social (de abril de 1964 a dezembro de 1965). Após essas experiências marcantes, Sussekind ainda voltaria a ocupar uma posição estratégica na área do trabalho, quando no governo Geisel (1974-1978) recebe a incumbência de ser o homem chave do Brasil junto à Organização Internacional do Trabalho, que ele freqüentava desde os anos 1950.

\section{Uma trajetória de mais de 50 anos}

Arnaldo Sussekind nasceu em 1917, em família de origem alemã por parte de pai. Uma família que, já em início do século XX, construíra para si uma tradição de nomes ligados ao direito. Seu pai, Frederico Sussekind, foi desembargador do Tribunal de Apelação do Distrito Federal e seu primo, Carlos Sussekind de Mendonça, um conhecido promotor. Portanto, teve infância tranqüila, em casa que possuía boa biblioteca e que era freqüentada por homens que "faziam justiça" no Rio de Janeiro. Estudou em boas escolas e, em 1939, formou-se como Bacharel pela Faculdade Nacional de Direito, da Universidade do Rio de Janeiro, futura Universidade do Brasil.

Ainda antes de se formar, por influência do pai, começa a estagiar no Conselho Nacional do Trabalho, onde logo depois se torna adjunto da Procuradoria. Porém, sua grande chance aparece em 1941, quando é nomeado Procurador Regional da Justiça do Trabalho em São Paulo. Em 1939, a Justiça do Trabalho fora instituída por Decreto-Lei do presidente Getúlio Vargas, chefe do Estado Novo, sendo que deveria ser efetivamente inaugurada no dia $1^{\circ}$ de maio de 1941, Dia do Trabalho. Para tanto, simultaneamente em todo o país, oito Conselhos Regionais deveriam começar a funcionar, sendo um deles o de São Paulo. É clara a importância dessa tarefa, confiada a um jovem com apenas dois anos de formado, que dela se desincumbe, voltando para o Rio.

Já no ano seguinte, recebe função ainda mais crucial em termos políticos. É escolhido como Assistente Técnico do ministro do Trabalho, Indústria e Comércio, isto é, vai ocupar um cargo de estrita confiança pessoal de um dos ministros mais influentes do período do Estado Novo. Por ser uma pessoa considerada pelo próprio ministro como capaz tecnicamente e leal politicamente, irá integrar, em 1943, 
uma seleta comissão (composta ainda por Luiz Augusto do Rego Monteiro, José de Segadas Viana, Oscar Saraiva e Durval Lacerda), encarregada da mais importante tarefa legislativa no campo do Direito do Trabalho realizada até hoje no Brasil: a elaboração da Consolidação das Leis do Trabalho, ou como se torna conhecida, da CLT. Nessa condição e oportunidade, ele transita nas mais altas esferas do poder e também da cultura jurídica na área trabalhista, tornando-se logo um de seus expoentes. Afinal, participara da feitura do que era o primeiro código dos direitos do trabalho, e que fora objeto de propostas e lutas há décadas. Algo que provavelmente só pode ocorrer porque o direito do trabalho era um direito novo no país e no mundo, abrindo-se em oportunidades para aqueles que estavam no lugar e na hora certos, como o jovem Sussekind que, além disso tudo, vinha de uma tradicional família de advogados e juristas.

Esse fato marcará a trajetória de vida de Sussekind e também suas idéias em relação aos direitos sociais, aos direitos trabalhistas e ao papel do Estado em questões que envolvem "justiça social”. Admirador de Getúlio Vargas e de sua obra de modernização social e econômica do país, Sussekind reconhece, até hoje, o acerto das medidas trabalhistas implementadas nos anos 1940, embora admita alguns excessos cometidos. Assim, para ele, se a legislação trabalhista está hoje superada em muitos aspectos, embora tendo sido revista ao longo de décadas, seu espírito foi e continua sendo acertado. Esse espírito, para ele, é o do papel protetor do Estado no mercado de trabalho, que não pode ser deixado sem legislação reguladora, especialmente em países com uma tradição jurídica intervencionista como a do Brasil.

Portanto, não é casual que com a queda de Vargas em 1945, ele abandone a cena política, retornando ao governo com o mesmo Vargas, em 1950. É nessa década e já durante o governo de Juscelino Kubitscheck, que terá contato mais assíduo com lideranças militares, sobretudo da Escola Superior de Guerra (ESG), uma vez que integra a Seção de Segurança Nacional do ministério do Trabalho. Nessa condição, participa das reuniões do Conselho de Segurança Nacional, onde passa a conviver com o general Castelo Branco, então diretor da ESG, e também com Ernesto Geisel, ambos futuros presidentes do regime militar que se estabelece em março de 1964. Torna-se conhecido como um homem que não tinha simpatias pelo comunismo, nem por João 
Goulart (o vice-presidente de Juscelino e também de Jânio Quadros), que se tornará presidente do Brasil em setembro de 1961, para ser derrubado por um golpe em 1964.

São todas essas credenciais que o levarão a ser convidado, primeiro por Ranieri Mazilli, para um curto período, e depois por Castelo Branco, definitivamente, para ocupar o ministério do Trabalho, logo após o movimento militar. Uma função que aceita, explicando, em seu depoimento, que o governo Castelo não pretendia atacar os direitos dos trabalhadores, ao contrário. Segundo Sussekind, nesse momento, se muitas foram as intervenções repressivas nos sindicatos, com a instalação de juntas de interventores, isso foi um preço a pagar pela infiltração comunista e pela prática da corrupção nos sindicatos. Para ele, relembrando o período mais de trinta anos depois, foi preferível realizar intervenções do que simplesmente fechar os sindicatos, como muitos militares influentes no governo desejavam.

Nessa retrospectiva de sua ação como ministro do Trabalho de Castelo Branco, Sussekind situa a resistência que comandou contra as investidas de militares, que queriam acabar com os sindicatos, e de empresários e ministros, que queriam acabar com a estabilidade do emprego e diminuir a pauta dos direitos dos trabalhadores de forma geral, com a eliminação, por exemplo, do $13^{\circ}$ salário. Segundo sua ótica, esse foi um momento de muitos ataques contra os direitos trabalhistas e sua atuação, apoiada pelo primeiro presidente militar, foi a de minimizar perdas e garantir posições, em situação muito delicada. Aliás, é interessante observar como, no ano de 2001, ele lamente que Castelo não tenha conseguido fazer do civil Bilac Pinto seu sucessor e, com isso, acabado o ciclo revolucionário, que teria então durado alguns poucos anos e não duas décadas, como durou.

Sussekind deixaria o ministério antes do fim do governo Castelo para, por sua escolha, tornar-se ministro do Superior Tribunal do Trabalho, a mais alta corte trabalhista do Brasil. Ascende a essa condição por nomeação do presidente e por ter carreira como Procurador da Justiça do Trabalho desde os anos 1940. Manterá esse cargo até se aposentar, o que coincide com a chegada do general Ernesto Geisel à presidência da República. Segundo depoimentos de ambos, Geisel (D’Araújo \& Castro, 1997, p. 267) e Sussekind (Gomes \& Peçanha, 2000), ele seria, mais uma vez convidado a ocupar a pasta do Trabalho e Previdência 
Social. Não aceita por razões de saúde, mas será um importante colaborador de Geisel. Uma espécie de "embaixador" do Brasil na Organização Internacional do Trabalho (OIT), onde, aliás, o país vinha sendo denunciado por associações internacionais de trabalhadores.

Durante os anos 1980 e 1990, abre escritório no Rio e continua a acompanhar os debates sobre mudanças na legislação trabalhista, debates esses que se intensificam a partir dos dois governos de Fernando Henrique Cardoso (1995-2002), para culminarem com o encaminhamento do projeto de flexibilização da CLT, aprovado pela Câmara dos Deputados em 4 de dezembro de 2001. Aprovado pela Câmara, mas não pelo Senado, que só o examinará durante o ano de 2002, ano de campanhas eleitorais, com todos os desdobramentos e implicações que eleições produzem em qualquer país do mundo.

\section{Direito do trabalho, reforma da CLT e o papel da OIT}

A trajetória de Arnaldo Sussekind é pródiga em evidências de uma rápida ascensão profissional e política, em parte explicada pelo prestígio e contatos de sua família (de seu pai, em particular), em parte vinculada à audácia e preparo do próprio Sussekind, e em parte compreensível pela associação do que Maquiavel chamou de sorte e virtu. De toda forma, o traço mais forte que ressalta dessa trajetória, muitas vezes afirmado em seu depoimento, é o compromisso com uma concepção de direito social, em geral, e de direito trabalhista, em especial, que consagra a necessidade de intervenção do Estado nas relações sociais, por meio de "leis escritas", de forma a impedir que as "leis de mercado" prevaleçam. Uma intervenção eminentemente protetiva dos direito sociais, compreendidos como parte de um pacto político mais amplo firmado entre Estado e Sociedade.

Uma concepção que, sem dúvida, teve amplo compartilhamento político exatamente no momento de formação jurídica de Sussekind: as décadas de 1930 e 1940. Mas seu depoimento revela que sua adesão a uma concepção de "Estado social", como ele chama e que vê hoje sob ameaça, não se deve apenas a razões de socialização política conjuntural. Ela se ancora em um entendimento intelectual do que é o Direito do Trabalho e de qual é a tradição jurídica brasileira nesse campo; um entendimento sólido que não sofre abalos significativos em função 
do passar do tempo e da mudança das circunstâncias mais imediatas. Um tipo de adesão a princípios jurídicos que são também entendidos como éticos, e que, como tais, são acreditados como tendo longa duração.

Talvez dessa forma se possa compreender melhor porque o único membro da comissão que elaborou a CLT durante a ditadura Vargas, e que foi o primeiro ministro do Trabalho do regime militar iniciado em 1964, seja hoje, com 81 anos, a voz mais ouvida e respeitada nas críticas empreendidas ao projeto governamental que quer flexibilizar as leis trabalhistas no Brasil. Um homem cuja trajetória está vinculada a governos autoritários, que aceita críticas dirigidas à legislação que ajudou a construir, mas que condena o momento, a maneira e a natureza das transformações que estão sendo encaminhadas pelo governo brasileiro, e que vê como ilustrativas do que se quer fazer com o Direito do Trabalho nesse início de século XXI, em todo o mundo.

De forma breve e talvez correndo o risco de algum simplismo, certos pontos do depoimento de Arnaldo Sussekind podem ser destacados para a melhor compreensão dos argumentos mais gerais que procuram se opor à proposta de desmontagem dos direitos do trabalho que ocorre, com variações, internacionalmente. Durante sua entrevista, é bom observar, essa questão não ganhou a urgência que veio a ter depois, pois sabemos que o "trabalho de memória" é informado pelo presente e que a própria rememoração de fatos é uma ação que visa ter efeitos imediatos para o narrador e seus ouvintes. Assim, a grande característica da entrevista está relacionada a uma certa representação do Direito do Trabalho como integrante do estoque de "direitos do homem, absolutos e naturais", inaugurados pela Revolução Francesa. Para Sussekind, mas obviamente não apenas para ele, uma vez que se trata de uma tradição de gênese construída nesse campo do saber jurídico, os direitos do trabalho são um desdobramento e uma complementação da luta pela cidadania em seu sentido lato, ou seja, de uma luta pela humanização das condições sociais que permitem "a riqueza das nações".

Por essa razão, o Direito do Trabalho, diferentemente de outros, nasceu internacional e como parte da Declaração Universal dos Direitos do Homem. Uma filiação de raiz iluminista que se bifurca em uma tradição de linha anglo-saxônica (a dos contratos prevalentes entre as partes) e uma tradição de linha romano-germânica (a da lei, do direito escrito), essa última seguida pelo Brasil. A distinção é significativa, mas 
não altera o ponto central da análise, que é o de destacar que esse conjunto de normas, valores e práticas surgiu como um grande arcabouço após a Primeira Guerra Mundial, em 1919, pelo Tratado de Versalhes. Isso fez com que ele existisse, preliminarmente, como um direito internacional e não nacional. Isso também fez com que ele se voltasse para o combate ao trabalho escravo e a todas as condições de trabalho que ameaçassem a vida do trabalhador e a natalidade da própria humanidade, donde a preocupação com a mulher e a infância.

Bandeiras formuladas durante a segunda década do século XX, quando poucos países eram industrializados e menos ainda aceitavam a possibilidade de qualquer tipo de regulamentação do mercado de trabalho de suas economias. Contudo, foi esse espírito, articulado internacionalmente, que direcionou e pressionou pela adoção de normas em todo o mundo. Seria ainda ele, evidentemente atualizado, que continuaria a presidir o entendimento do núcleo dos direitos do trabalho, para além das realidades de tempo e espaço, e que deveria prevalecer no Brasil e em outros países, mesmo no início do século XXI. Isso porque, nessa visão mais larga, os direitos sociais do trabalho apresentam-se como um grande pacto político das nações com as condições de vida e trabalho de sua população, tudo isso gerido e articulado por uma grande associação voluntária: a Organização Internacional do Trabalho, OIT.

Dessas formulações, de imediato, duas implicações se podem tirar. Primeira: o debate sobre direitos do trabalho não é uma questão socioeconômica, derivada da situação conjuntural de qualquer mercado nacional; é uma questão política, que indica o tipo de pacto que um Estado está realizando com a Sociedade, isto é, que tipo de sociedade se está projetando em termos materiais e principalmente de valores. Segunda: enquanto estoque de direitos e tradição construída internacionalmente, as transformações na legislação trabalhista de um país não poderiam violar acordos sancionados junto a OIT, não porque essa associação tenha poderes policiais de repressão, mas porque ela aponta para normas consideradas inegociáveis, no que se refere justamente aos chamados "direitos do homem trabalhador".

São tais ponderações de fundo que, na verdade, balizam as observações de Sussekind quando do debate pela flexibilização da CLT no Brasil. Assim, antes de tudo, ele chama atenção para o fato de que a flexibilização já existe, sendo autorizada pela Constituição de 1988 em 
vários casos: em matéria de salário (redução mediante acordo); em matéria de jornada de trabalho (o banco de horas) e em matéria de despedida do empregado (o Fundo de Garantia por Tempo de Serviço, FGTS). Em seguida, ele adverte que qualquer mudança em corpo legislativo dessa importância e teor deve ser realizada em momento adequado e por pessoas especializadas. No caso em questão, o Brasil atravessa grande crise de desemprego, o que enfraquece qualquer sindicato e permite ao patronato o encaminhamento de acordos que podem em nada beneficiar o trabalhador, preocupado somente em manter seu posto de trabalho. Daí a impropriedade do projeto e a proposta alternativa de reforma da CLT por meio de uma "lei delegada": um projeto a ser elaborado por comissão de especialistas autorizada pelo Congresso e pelo Executivo, para ser votado posteriormente. E finalmente, ele ressalta a existência de convenções internacionais e, de tratados firmados pelo Brasil que não devem ser violados por medidas precipitadas e inadequadas.

É esse aspecto que aqui ganha relevo particular, pois levanta a reflexão do papel que instâncias internacionais podem ter no processo político de países como o Brasil. Não porque a OIT possa ter qualquer tipo de ingerência direta no que diz respeito à legislação trabalhista de uma nação, mas porque pode receber denúncias, como já recebeu ao longo de sua existência, pressionando para que certas normas sejam adotadas e outras não sejam alteradas. O espaço de resistências a transformações, como as que se observam hoje, poderia assim ser ampliado e fortalecido com a dinamização da OIT.

Aliás, para Sussekind, o avanço da desregulamentação dos direitos do trabalho em todo mundo vem caminhando ao lado do enfraquecimento da OIT. Dois processos paralelos e que se alimentam mutuamente. Tendo participado de reuniões da OIT desde 1944, integrando seu Conselho Jurídico (1957), sua Comissão de Peritos (1969) e seu Conselho de Administração (1974) ${ }^{4}$, Sussekind vê com pessimismo o

4 O Conselho de Administração é a instância mais importante da OIT, correspondendo a uma direção colegiada e restrita dessa organização. O CA é integrado por dez países membros não eletivos e por 18 países membros eleitos para um mandato que se renova de três em três anos. A eleição segue uma lógica de representação continental e orienta-se por um gentleman agreement, uma vez que as indicações realizadas pelos integrantes de uma região costumam ser aceitas pela OIT. 
desmantelamento dessa e de outras organizações internacionais. Para ele, sobretudo no caso dos direitos do trabalho, francamente universais e humanitários, o revigoramento de tais instituições seria base segura para uma luta contra a permanência de concepções neoliberias, que arriscam normas inegociáveis, lançando os trabalhadores abaixo de um patamar mínimo de segurança e respeito. Um retrocesso diante do qual ele tem, em curto prazo, uma posição razoavelmente cética e que vem acompanhando há algum tempo.

Com essa preocupação, em seu depoimento Sussekind realiza uma periodização da história da OIT, situando três grandes tempos, a que corresponderiam etapas do desenvolvimento dos direitos do trabalho. Numa primeira fase, que decorreria da criação da OIT, em 1919, aos anos 1950, a instituição teria tido um papel fundamental na elaboração detalhada de normas de trabalho, que visavam influir e influíram de fato, em sua avaliação, na adoção de leis trabalhistas em diversos países. A OIT atuou assim em termos normativos e também desenvolvendo toda uma cooperação técnica que, pelo desenvolvimento de programas, estimulava a adoção de medidas protetivas ao trabalho. Foi o tempo das Convenções internacionais que, ratificadas, vinham a se transformar em muitas leis nacionais. Isso, segundo ele, foi possível em função dos dois períodos do pós-guerra e do medo da influência soviética: do medo do comunismo. Isso fazia com que países como os EUA, a Alemanha e a Inglaterra fizessem doações à OIT, com as quais a instituição ganhava prestígio, força e podia, objetivamente, implementar seus programas de cooperação técnica, em especial nos países "subdesenvolvidos"5.

Embora Sussekind reconheça que, nessas décadas, muitos eram os "sistemas legislativos nacionais", uns bem pouco regulados, como os EUA, e outros bem detalhados, como o Brasil, de uma forma geral a importância da regulamentação e do papel protetivo do Estado estavam assegurados. Esse foi o grande ganho e a marca da primeira fase.

5 A OIT tem uma Comissão de Atividades Práticas que aprova verbas para programas de cooperação nos países interessados. Ela tem também um Centro de Formação Técnica e Profissional que é disputado em função do prestígio e qualificação que oferece. Esses são exemplos concretos do poder de atração e barganha que a OIT possuía sobre países em desenvolvimento. 
Na segunda, que se abre no início dos anos 1960, sob impacto do processo de descolonização da África, o papel da OIT continuou forte, embora com maior flexibilidade. Ou seja, como um grande conjunto de novas e diversificadas nações precisava ser considerado, não era mais possível estabelecer convenções minuciosas, como antes. A estratégia foi a de montar uma espécie de dupla possibilidade de acordos internacionais. As convenções propriamente ditas, que defendiam princípios gerais e inegociáveis, considerados básicos em relação a direitos do trabalho e que deviam ser firmadas por todas as nações; e as chamadas recomendações, acopladas às convenções, que visavam ao detalhamento de direitos mais específicos e que podiam ou não ser firmadas por todos os países membros da OIT.

Nesse período, que se estende até a década de 1980, a OIT continuou a usar seus recursos de atração junto a governos para conseguir a ratificação de suas convenções, recebendo e processando muitas denúncias de desrespeito à legislação do trabalho, sobretudo referentes a países como Portugal, Espanha, Brasil e África do Sul. Seu poder de aplicação de sanções morais continuava razoável, razão pela qual, apesar da perda de influência efetiva, a organização permaneceu como um foro importante, inclusive para os países denunciados, que nele procuravam fazer sua defesa. Portanto, segundo sua avaliação, embora muitas normas não estivessem sendo aplicadas, os princípios fundamentais que regiam a concepção do Direito do Trabalho permaneciam de pé.

Já na terceira fase que delimita, é essa a grande perda e mudança. O que está em risco não é o cumprimento de uma ou outra norma, mas a própria idéia de que normas mínimas de trabalho precisam existir para que a saúde física e moral do trabalhador seja respeitada. Esse novo período inaugura-se, sempre seguindo o depoimento de Sussekind, no fim da década de 1980, sob o impacto do chamado "fim do socialismo" e da ascensão do neoliberalismo. Não só o apoio financeiro, através de doações, foge da OIT, mas também o interesse das nações mais ricas em permanecer ratificando suas convenções e buscando a sanção de outros países. O melhor exemplo dessa grande perda de vigor é o fracasso da OIT em incluir qualquer tipo de cláusula social-trabalhista em debates da Organização Internacional de Comércio. As proposições da OIT são ignoradas tanto pelos foros internacionais, quanto pelos projetos de reformas na legislação de trabalho de vários 
países. É o caso explícito do Brasil que, na proposta aprovada pela Câmara, viola acordos internacionais anteriormente assinados, sem qualquer tipo de preocupação. Um péssimo sinal, segundo ele.

Um sinal de perda de princípios contra a qual a OIT tem que lutar, atuando por meio de seus estudos e da tradição que construiu ao longo do século XX. Ao menos, para Sussekind, ela ainda pode e deve ser um espaço de luta, e é para tal advertência que esse texto quer contribuir.

\section{Referências bibliográficas}

D'ARAÚJO, Maria Celina \& CASTRO Celso. Geisel. Rio de Janeiro, FGV, 1997. GOMES, Angela de Castro. "O ministério da revolução". In: GOMES, A.C. (org.). Trabalho e previdência social: sessenta anos em debate. Rio de Janeiro, FGV, 1992.

GOMES, Angela de Castro \& PEÇANHA, Elina. Depoimento de Arnaldo Sussekind. Maio/junho de 2000 (inédito).

Resumo: O texto discute o atual processo de flexibilização dos direitos do trabalho no Brasil, a partir das últimas propostas de reformulação da Consolidação das Leis do Trabalho (CLT), datadas de fim do ano de 2001. Para tanto, utiliza a entrevista de Arnaldo Sussekind, jurista ligado à formulação dessa legislação, que é, hoje, o único sobrevivente da comissão que, em 1943, elaborou a CLT. Sua posição, contrária à referida flexibilização, aponta para a importância da OIT como um espaço de defesa da concepção de Direito do Trabalho, alertando para o fato de que a experiência internacional não atesta vantagens para 0 conjunto dos trabalhadores.

Palavras-Chave: direito do trabalho; trabalhadores e CLT; memória e trabalho.

The Labor Legislation in the Beginning of the 21 st Century: Testimony of ARNALDO SUSSEKIND

ABstract: The text discusses the current process of flexibility of the rights of the work in Brazil, starting from the last proposals of reformulation of the Consolidation of the Laws of the Work (CLT), dated of end of the year of 2001. For so much, it uses Arnaldo Sussekind's interview. Jurist linked to the formulation of that legislation, he is, 
today, the only remaining member of the commission, which, in 1943, elaborated CLT. His position, opposed to the flexibilization, stresses the importance of OIT as a forum for the defense of the conception of the labor legislation, alerting for the fact that the international experience doesn't attest advantages for the workers' group.

KEYWORDS: labor legislation; workers and CLT; memory and work. 